\title{
Aplicação intra-mamária de curcumina em ovelhas com mastite subclínica e ovelhas saudáveis: efeito sobre produção e qualidade do leite
}

\author{
Intramammary application of curcumin in ewes with subclinical mastitis and healthy ewes: effect \\ on milk production and quality \\ Aplicación intramamaria de curcumina en ovejas con mastitis subclínica y ovejas sanas: efecto \\ sobre la producción y calidad de la leche
}

\author{
Bruno Giorgio de Oliveira Cécere \\ ORCID: https://orcid.org/0000-0003-3135-4787 \\ Universidade do Estado de Santa Catarina, Brasil \\ E-mail: brunocecere@ hotmail.com \\ Guilherme Luiz Deolindo \\ ORCID: https://orcid.org/0000-0001-9734-6902 \\ Universidade do Estado de Santa Catarina, Brasil \\ E-mail: guilhermeluizd@outlook.com \\ Vitor Luiz Molosse \\ ORCID: https://orcid.org/0000-0003-3652-8088 \\ Universidade do Estado de Santa Catarina, Brasil \\ E-mail: vitor.molosse@gmail.com \\ Lilian Kolling Girardini \\ ORCID: https://orcid.org/0000-0002-2891-7756 \\ Universidade do Oeste de Santa Catarina, Brasil \\ E-mail: 1ilian.kolling@unoesc.edu.br \\ Marcelo Vedovatto \\ ORCID: https://orcid.org/0000-0002-9050-6990 \\ Universidade do Estado do Mato Grosso do Sul, Brasil \\ E-mail: vedovatto@zootecnista.com.br \\ Aleksandro Schafer da Silva \\ ORCID: https://orcid.org/0000-0001-9606-5447 \\ Universidade do Estado de Santa Catarina, Brasil \\ E-mail: aleksandro_ss@yahoo.com.br
}

\begin{abstract}
Resumo
O objetivo do trabalho foi avaliar o efeito da aplicação intra-mamária de curcumina em ovelhas com mastite subclínica e ovelhas saudáveis sobre produção de leite, qualidade do leite e saúde de ovelhas. Para isso foi realizado dois experimentos: Experimento I: 10 ovelhas com mastite subclínica crônica foram divididas em dois grupos de cinco ovelhas cada: a) controle, foi aplicado $3 \mathrm{~mL}$ de óleo mineral via intra-mamária; b) curcumina, aplicado $2 \mathrm{mg}$ de curcumina diluída em óleo mineral via intra-mamária. Houve efeito do tratamento, isto é, ovelhas que receberam a aplicação de curcumina tiveram maior produção de leite. Houve o efeito do tratamento para percentagem de proteína no leite, assim como tendencia de efeito do tratamento para lactose e solidos totais; com destaque para menores níveis de proteína, lactose e sólidos não gordurosos nas ovelhas do grupo curcumina comparado ao controle. Verificamos uma interação entre tratamento versus dia para proteína no leite nos dias 7 e 14 após aplicação; menor no grupo curcumina. Efeito do dia foi verificado para contagem de eritrócitos e leucócitos, assim como a concentrações de hemoglobina em ambos os grupos. Para o experimento II usamos 80 ovelhas divididas em 4 grupos: controle, T2, T3 e T4 (2, 3 e $4 \mathrm{mg}$ de curcumina diluída em óleo mineral via intra-mamaria, respectivamente). Efeito do dia foi observado para o grupo T2, isto é, houve um aumento na produção de leite do dia 1 para 20. A contagem de células somáticas (CCS) sofreu efeito do tratamento, dia e interação entre tratamento versus dia. O maior CCS foi observado no grupo T4. Do grupo de ovelhas, 17 tiveram problemas na glândula mamaria após a aplicação dos quatro tratamentos, sendo que cinco ovelhas desenvolveram uma grave mastite ambiental e morreram; e os demais animais também testaram positivos para mastite subclínica no teste da raquete (Califórnia Mastite Teste). De modo geral, o uso da curcumina via intra-mamaria nas doses testadas não tem efeito curativo, assim como quando usado em ovelhas saudáveis causa efeito negativo, afetando a qualidade do leite (elevou CCS). Além disso, a aplicação de produtos intra-mamários (óleo mineral ou óleo + curcumina) são um risco elevado para o animal; portanto, não recomendamos. Palavras-chave: Mastite; Extrato Herbal; Ovinos.
\end{abstract}




\begin{abstract}
The objective of this work was to evaluate the effect of intramammary application of curcumin in ewes with subclinical mastitis and healthy ewes on milk production, milk quality and ewes health. For this, two experiments were carried out: Experiment I: 10 ewes with chronic subclinical mastitis were divided into two groups of five ewes each: a) control, $3 \mathrm{~mL}$ of mineral oil was applied intra-mammary; b) curcumin, applied $2 \mathrm{mg}$ of curcumin diluted in mineral oil, intra-mammary. There was a treatment effect, that is, ewes that received the application of curcumin had higher milk production. There was a treatment effect for the percentage of protein in milk, as well as a trend of treatment effect for lactose and total solders; with emphasis on lower levels of protein, lactose and non-fat solids in the ewes of the curcumin group compared to the control. We found an interaction between treatment versus day for milk protein on days 7 and 14 after application; lower in the curcumin group. Day effect was verified for erythrocyte and leukocyte counts, as well as hemoglobin concentrations in both groups. For experiment II we used 80 ewes divided into 4 groups: control, T2, T3 and T4 (2, 3 and $4 \mathrm{mg}$ of curcumin diluted in mineral oil via intra-mammary, respectively). Day effect was observed for the T2 group, that is, there was an increase in milk production from day 1 to 20. Somatic cell count (SCC) was effected by treatment, day and interaction between treatment versus day. The highest SCC was observed in the T4 group. Of the group of ewes, 17 had problems in the mammary gland after applying the four treatments, and five ewes developed severe environmental mastitis and died; and the other animals also tested positive for subclinical mastitis in the racket test (California Mastitis Test). In general, the use of curcumin intra-mammary at the doses tested has no curative effect, as well as when used in healthy sheep, it has a negative effect, affecting the quality of the milk (increased CCS). Furthermore, the application of intra-mammary products (mineral oil or oil + curcumin) is a high risk for the animal; therefore, we do not recommend.
\end{abstract}

Keywords: Mastitis; Herbal Extract; Sheep.

\title{
Resumen
}

El objetivo de este trabajo fue evaluar el efecto de la aplicación intramamaria de curcumina en ovejas con mastitis subclínica y ovejas sanas sobre la producción de leche, la calidad de la leche y la salud de las ovejas. Para ello se realizaron dos experimentos: Experimento I: Se dividieron 10 ovejas con mastitis subclínica crónica en dos grupos de cinco ovejas cada uno: a) control, se aplicó $3 \mathrm{~mL}$ de aceite mineral intramamario; b) curcumina, se aplican $2 \mathrm{mg}$ de curcumina diluidos en aceite mineral intramamario. Hubo un efecto de tratamiento, es decir, las ovejas que recibieron la aplicación de curcumina tuvieron mayor producción de leche. Hubo un efecto del tratamiento para el porcentaje de proteína en la leche, así como una tendencia del efecto del tratamiento para la lactosa y soldaduras totales; con énfasis en niveles más bajos de proteína, lactosa y sólidos no grasos en las ovejas del grupo de curcumina en comparación con el control. Encontramos una interacción entre el tratamiento versus el día para la proteína de la leche los días 7 y 14 después de la aplicación; más bajo en el grupo de la curcumina. Se verificó el efecto día para los recuentos de eritrocitos y leucocitos, así como las concentraciones de hemoglobina en ambos grupos. Para el experimento II se utilizaron 80 ovejas divididas en 4 grupos: control, T2, T3 y T4 (2, 3 y $4 \mathrm{mg}$ de curcumina diluidos en aceite mineral vía intra-mama, respectivamente). Se observó un efecto de día para el grupo T2, es decir, hubo un aumento en la producción de leche del día 1 al 20. El recuento de células somáticas (CCS) se efectuó por el tratamiento, el día y la interacción entre el tratamiento y el día. La CCS más alta se observó en el grupo T4. Del grupo de ovejas, 17 tuvieron problemas en la glándula mamaria después de aplicar los cuatro tratamientos, y cinco desarrollaron mastitis ambiental severa y murieron; y los otros animales también dieron positivo por mastitis subclínica en la prueba de raqueta (Prueba de Mastitis de California). En general, el uso de curcumina intramamaria a las dosis probadas no tiene efecto curativo, así como cuando se usa en ovejas sanas tiene un efecto negativo, afectando la calidad de la leche (aumento de CCS). Además, la aplicación de productos intramamarios (aceite mineral o aceite + curcumina) es de alto riesgo para el animal; por lo tanto, no lo recomendamos.

Palabras clave: Mastitis; Extracto de hierbas; Oveja.

\section{Introdução}

A cadeia da ovinocultura leiteira no Brasil e no mundo possui características altamente favoráveis para um crescimento exponencial, fato esse que está ligado ao alto valor agregado e da qualidade dos produtos lácteos advindos desses animais, logo tal atividade anda atrelado com o mercado consumidor (Rohenkohl et al., 2015). A alta demanda por tais produtos está inteiramente associada a composição do leite produzido pelas ovelhas, principalmente os teores de gordura que giram em torno de uma média de $8 \%$, variando conforme fase de lactação do animal, raça, alimentação, entre demais fatores (Park et al., 2007). Um dos grandes problemas que os produtores de leite enfrentam está relacionado a encontrar animais do rebanho acometidos por uma inflamação no sistema mamário, normalmente acometida por um patógeno ou por alguma lesão na região, fenômeno esse denominado de mastite, conhecido mundialmente e altamente prejudicial a produção e qualidade do leite e principalmente a saúde dos animais (Leitner et al. 2004; Veríssimo et al. 2010). Entretanto, o tratamento imediato aos 
animais que apresentam tal inflamação baseia-se no uso de antibióticos sintéticos, toda via, o mercado consumidor está cada vez mais preocupado com o desenvolvimento acelerado da resistência bacteriana cruzada animal-humano através dos produtos de origem animal (Abdalhamed et al. 2018).

$\mathrm{Na}$ busca por mudanças no uso indiscriminado de medicamentos sintéticos, os extratos herbais devido as suas características peculiares e semelhantes, os mesmos estão comumente sendo estudados. A curcumina, extrato obtido do rizoma da Curcuma longa, vem sendo alvo de inúmeras pesquisas por ser um polifenol com propriedades bioativas benéficas, com destaque para a forte atividade antioxidante em ovinos suplementados com curcumina (Molosse et al. 2019, Jaguezeski et al. 2018). Galli et al. (2018) mostraram efeito anti-inflamatório, antioxidante e anticoccidiano em poedeiras suplementadas com curcumina, fato esse que demonstra sua utilização em diferentes espécies e para diferentes objetivos. Toda via, no presente estudo, pensando em otimização do uso da curcumina devida a mesma ser altamente metabolizável e ter baixa disponibilidade (Noorafshan \& Ashkani-Esfahani 2013). Portanto, o objetivo do estudo foi avaliar se a aplicação intra-mamaria de curcumina em ovelhas com mastite subclínica e ovelhas saudáveis tem efeitos positivos sobre produção de leite, qualidade do leite e saúde de ovelhas.

\section{Metodologia}

Esta pesquisa teve um caráter exploratório e quantitativo (Pereira et al. 2018). O projeto foi aprovado pelo Comitê de Ética no uso de Animal na Pesquisa da Universidade do Estado de Santa Catarina-UDESC, sob o protocolo nº 9781070619.

\subsection{Curcumina}

A curcumina utilizada no Experimento I foi adquirida da Sigma-Aldrich ${ }^{\circledR}$ (China) contendo $94 \%$ de pureza. Já a curcumina utilizada no Experimento II foi adquirida também da Sigma-Aldrich ${ }^{\circledR}$ (China), porém a pureza era de $80 \%$.

\subsection{Produção das bisnagas}

Foram utilizadas seringas intramamárias de bico removível 12,25mL (Embalabor® - Brasil) que possuem cânula fina e curta, própria para a anatomia do teto ovino. Inicialmente foram realizadas as pesagens da curcumina de acordo com cada tratamento; posteriormente foi diluída em óleo mineral em tubos falcon estéreis, com auxílio de agitador tipo vórtex. Após a diluição completa, as seringas foram preenchidas com $3 \mathrm{~mL}$ do produto de forma asséptica em capela de fluxo laminar. A quantidade aplicada em cada papila foi de $3 \mathrm{~mL}$ corrobora com estudo anterior já realizado em ovelhas (Deolindo et al. 2021).

\subsection{Experimento I - ovelhas com mastite}

O experimento foi conduzido em uma propriedade comercial localizada no município de Chapecó - SC (Brasil). Foram utilizadas 10 ovelhas alojadas no mesmo recinto, diagnosticadas com mastite subclínica crônica (Califórnia Mastite Teste - CMT), divididas em dois grupos: cinco ovelhas para o grupo controle, aplicado $3 \mathrm{~mL}$ de solução de óleo mineral por compartimento mamário; e cinco animais para o grupo curcumina, que recebeu $2 \mathrm{mg}$ de curcumina diluído em $3 \mathrm{~mL}$ de óleo mineral via intra-mamária. Foi realizada três aplicações por animal (1 por compartimento mamário) após a ordenha em intervalo de $12 \mathrm{~h}$ cada. Os tetos foram devidamente higienizados com álcool (70\%) antes de cada aplicação para reduzir os riscos de contaminação.

\subsection{Experimento II - ovelhas saudáveis}

Foram utilizadas 80 ovelhas saudáveis, divididas em quatro tratamentos, alojadas em baias com 20 animais cada: grupo controle, foi aplicado $3 \mathrm{~mL}$ de solução de óleo mineral; grupo T2, T3 e T4, corresponde a aplicação de 2, 3 e $4 \mathrm{mg}$ de 
curcumina diluída em $3 \mathrm{~mL}$ de óleo mineral via intra-mamária, respectivamente. Foi realizada três aplicações por animal (1 por compartimento mamário) após a ordenha em intervalo de $12 \mathrm{~h}$ cada. Os tetos foram devidamente higienizados com álcool (70\%) antes de cada aplicação para minimizar os riscos de contaminação.

\subsection{Coleta de amostras e análises de laboratório}

No experimento I, as coletas de leite e mensuração de leite produzido foram realizadas no dia 1,7 e 14 de experimento. Para as coletas os tetos foram limpos e desinfetados com álcool (70\%), e os três primeiros jatos de leite foram descartados, seguidos por coleta manual de leite $(50 \mathrm{~mL})$ para a análise centesimal e a contagem de células somáticas (CCS). Amostra de sangue também foram realizadas no dia 1, 7 e 14 de experimento, com animais em jejum, pela veia jugular. $\mathrm{O}$ sangue foi alocado em tubos contendo EDTA como anticoagulante $(4 \mathrm{~mL})$ para realização de hemograma.

No experimento II, a mensuração da produção de leite foi feita no dia 1 e 20; assim como as coletas de leite foram realizadas nos dias 1, 3 e 14 pós aplicação de curcumina intra-mamaria usadas para mensurar CCS.

\subsubsection{Mensuração do leite}

A ordenha dos animais foi mecanizada e realizada duas vezes ao dia (05:00 e 16:00 horas). A verificação volumétrica individual do leite foi realizada para todos os animais, obtida por meio de um medidor tipo "Milk Meter" (True Test ${ }^{\circledR}$, Auckland, Nova Zelândia), medindo o volume produzido nas ordenha da manhã e da tarde.

\subsubsection{Contagem de células somáticas}

A contagem de célula somáticas (CCS) foi feita em contador digital (Ekomilk Scan Somatic Cell Analyzer®), equipamento de campo utilizado para contagem de CCS em leite de vaca; porém também eficiente para leite de ovinos. Usamos um volume de $50 \mathrm{~mL}$ de leite para CCS.

\subsubsection{Composição centesimal do leite}

A composição centesimal de gordura, proteína, lactose e sólidos não gordurosos no leite foi determinada em analisador infravermelho (LactoStar Funke Gerber®). O equipamento automático utiliza $30 \mathrm{~mL}$ de leite para análise e resultados são apresentados em percentagem.

\subsubsection{Isolamento das bactérias}

As amostras foram cultivadas em ágar sangue suplementado com 5\% de sangue de ovelha desfibrinado, ágar MacConkey e ágar Sabouraud. As placas foram incubadas a $37^{\circ} \mathrm{C}$ por 24 a $72 \mathrm{~h}$ os microrganismos foram identificados de acordo com as características morfológicas descritas pelo National Mastitis Council (2004) e Markey et al. (2013).

\subsubsection{Hemograma}

O número de eritrócitos e leucócitos totais, hematócrito, bem como a concentração de hemoglobina (Hb) foram medidos por meio de um aparelho automático (SYSMEX KX-21N).

\subsection{Análise estatística}

Os dados foram analisados usando o 'procedimento MIXED’ do SAS (SAS Inst. Inc., Cary, NC, EUA; versão 9.4), para determinar o grau de liberdade do denominador para o teste de efeitos fixos. Todos os resultados foram analisados como medidas repetidas e foram testados para efeitos fixos de tratamento, dia e tratamento $\times$ dia, usando animal (tratamento) como 
efeito aleatório. Os resultados de dia 1 foram incluídos como uma covariável independente. Além disso, para essas variáveis a fim de gerar a média por tratamento, os resultados dia 1 foram removidos do conjunto de dados, mas foram mantidos como covariável. A estrutura de covariância autorregressiva de primeira ordem foi selecionada de acordo com o critério de informação de Akaike. As médias foram separadas usando o método PDIFF e todos os resultados foram relatados como LSMEANS seguido por erro padrão. A significância foi definida quando $\mathrm{P} \leq 0,05$ e houve tendência quando $\mathrm{P}>0,05$ e $\leq 0,10$.

\section{Resultados}

\subsection{Experimento I}

Os resultados de produção de leite, composição centesimal do leite e CCS estão descritos na Tabela 1. Houve efeito do tratamento, isto é, ovelhas que receberam a aplicação de curcumina tiveram maior produção de leite. Houve o efeito do tratamento para percentagem de proteína no leite, assim como tendencia de efeito do tratamento para lactose e soldos totais; com destaque para menores níveis de proteína, lactose e sólidos não gordurosos nas ovelhas do grupo curcumina comparado ao controle. Verificamos uma interação entre tratamento versus dia para proteína no leite nos dias 7 e 14 após aplicação; menor no grupo curcumina.

Tabela 1. Produção de leite, composição centesimal e contagem de células somáticas de ovelhas que receberam 2 mg de curcumina intra-mamária (Experimento 1).

\begin{tabular}{|c|c|c|c|c|c|c|}
\hline \multirow{2}{*}{ Items } & \multicolumn{2}{|c|}{ Tratamento $\left(\right.$ Trat) $^{1}$} & \multirow{2}{*}{ EPM } & \multicolumn{3}{|c|}{$P$ - valor } \\
\hline & Controle & Curcumina & & Trat & Dia & Trat $\times$ Dia \\
\hline Produção de leite (g/dia) & & & & 0.05 & 0.59 & 0.25 \\
\hline d 1 & 875 & 925 & 109 & & & \\
\hline $\mathrm{d} 7$ & 655 & 985 & 109 & & & \\
\hline d 14 & 615 & 985 & 109 & & & \\
\hline Media $^{2}$ & $622^{\mathrm{b}}$ & $998^{\mathrm{a}}$ & 103 & & & \\
\hline Gordura (\%) & & & & 0.36 & $<0.01$ & 0.73 \\
\hline d 1 & $5.70^{\mathrm{B}}$ & $5.44^{\mathrm{B}}$ & 0.41 & & & \\
\hline $\mathrm{d} 7$ & $7.02^{\mathrm{A}}$ & $6.32^{\mathrm{B}}$ & 0.41 & & & \\
\hline d 14 & $7.11^{\mathrm{A}}$ & $6.96^{\mathrm{A}}$ & 0.41 & & & \\
\hline Media $^{2}$ & 7.11 & 6.57 & 0.38 & & & \\
\hline Proteína (\%) & & & & 0.05 & $<0.01$ & $\mathbf{0 . 0 3}$ \\
\hline d 1 & $3.38^{\mathrm{B}}$ & 3.44 & 0.13 & & & \\
\hline $\mathrm{d} 7$ & $3.99^{\mathrm{A}, \mathrm{a}}$ & $3.53^{\mathrm{b}}$ & 0.13 & & & \\
\hline d 14 & $4.22^{\mathrm{A}, \mathrm{a}}$ & $3.65^{\mathrm{b}}$ & 0.13 & & & \\
\hline Media $^{2}$ & $4.08^{\mathrm{a}}$ & $3.61^{\mathrm{b}}$ & 0.15 & & & \\
\hline Lactose $(\%)$ & & & & $\mathbf{0 . 0 7}$ & $<0.01$ & 0.21 \\
\hline d 1 & $5.04^{\mathrm{B}}$ & 5.00 & 0.17 & & & \\
\hline $\mathrm{d} 7$ & $5.56^{\mathrm{A}}$ & 5.13 & 0.17 & & & \\
\hline d 14 & $5.89^{\mathrm{A}}$ & 5.29 & 0.17 & & & \\
\hline Media $^{2}$ & $5.74^{\mathrm{a}}$ & $5.20^{\mathrm{b}}$ & 0.19 & & & \\
\hline Sólidos não gordurosos (\%) & & & & 0.06 & $<0.01$ & 0.21 \\
\hline d 1 & $9.43^{\mathrm{B}}$ & 9.36 & 0.35 & & & \\
\hline $\mathrm{d} 7$ & $10.5^{\mathrm{A}}$ & 9.64 & 0.35 & & & \\
\hline d 14 & $11.2^{\mathrm{A}}$ & 9.97 & 0.35 & & & \\
\hline Media $^{2}$ & $10.9^{\mathrm{a}}$ & $9.78^{\mathrm{b}}$ & 0.40 & & & \\
\hline $\operatorname{CCS}\left(\mathrm{x} 10^{3} \mathrm{cel}\right)$ & & & & 0.53 & 0.16 & 0.13 \\
\hline d 1 & 1731 & 3189 & 622 & & & \\
\hline $\mathrm{d} 7$ & 1954 & 840 & 674 & & & \\
\hline
\end{tabular}




\begin{tabular}{llll}
$\mathrm{d} 14$ & 1396 & 2435 & 622 \\
Media $^{2}$ & 1304 & 2114 & 560 \\
\hline
\end{tabular}

${ }^{1}$ Os tratamentos foram: Controle e Curcumina (tratamento curcumina representa os animais que receberam 2 mg de curcumina diluída em 3 $\mathrm{ml}$ de óleo mineral via intra-mamária).

${ }^{2}$ Os resultados de dia 1 foram removidos do conjunto de dados para gerar a média por tratamento na análise estatística (EPM - erro padrão da média).

A-B Na mesma coluna, diferem $(\mathrm{P} \leq 0,05)$ ou tendem a diferir $(\mathrm{P} \leq 0,10)$, sendo ilustrado por letras maiúsculas diferentes.

${ }^{\mathrm{a}-\mathrm{b}} \mathrm{Na}$ mesma linha, diferem $(\mathrm{P} \leq 0,05)$ ou tendem a diferir $(\mathrm{P} \leq 0,10)$, sendo ilustrado por letras minúsculas diferentes.

Fonte: Autores.

Resultados hematológicos foram apresentados na Tabela 2. Efeito do dia foi verificado para contagem de eritrócitos e leucócitos, assim como a concentrações de hemoglobina em ambos os grupos. No entanto, não houve efeito do tratamento ou interação entre tratamento versus dia para variáveis hematológicas analisadas.

Tabela 2. Hemograma das ovelhas que receberam $2 \mathrm{mg}$ de curcumina intra-mamária (Experimento 1).

\begin{tabular}{|c|c|c|c|c|c|c|}
\hline \multirow{2}{*}{ Items } & \multicolumn{2}{|c|}{ Tratamento (Trat) $^{1}$} & \multirow{2}{*}{ EPM } & \multicolumn{3}{|c|}{$P$ - valor } \\
\hline & Controle & Curcumina & & Trat & Dia & Trat $\times$ Dia \\
\hline Eritrócitos $\left(\mathrm{x} 10^{6} \mu \mathrm{L}\right)$ & & & & 0.17 & 0.01 & 0.45 \\
\hline d 1 & $9.12^{\mathrm{A}}$ & $9.26^{\mathrm{A}}$ & 0.18 & & & \\
\hline $\mathrm{d} 7$ & $8.51^{\mathrm{B}}$ & $8.72^{\mathrm{B}}$ & 0.18 & & & \\
\hline d 14 & $8.54^{\mathrm{B}}$ & $9.09^{\mathrm{AB}}$ & 0.18 & & & \\
\hline Media $^{2}$ & 8.49 & 8.95 & 0.19 & & & \\
\hline Hematócrito (\%) & & & & 0.44 & 0.79 & 0.54 \\
\hline d 1 & 42.8 & 41.9 & 5.62 & & & \\
\hline $\mathrm{d} 7$ & 47.2 & 39.3 & 5.62 & & & \\
\hline d 14 & 49.1 & 41.0 & 5.62 & & & \\
\hline Media $^{2}$ & 48.4 & 39.9 & 6.57 & & & \\
\hline Hemoglobina (g/dL) & & & & 0.25 & 0.04 & 0.34 \\
\hline $\mathrm{d} 1$ & $9.91^{\mathrm{A}}$ & $9.99^{\mathrm{A}}$ & 0.20 & & & \\
\hline d 7 & $9.39^{\mathrm{B}}$ & $9.55^{\mathrm{B}}$ & 0.20 & & & \\
\hline d 14 & $9.41^{\mathrm{B}}$ & $10.0^{\mathrm{A}}$ & 0.20 & & & \\
\hline Media $^{2}$ & 9.37 & 9.81 & 0.21 & & & \\
\hline Leucócitos (x10³ $\mu \mathrm{L})$ & & & & 0.92 & $<0.01$ & 0.24 \\
\hline d 1 & $6.39^{\mathrm{B}}$ & $6.60^{\mathrm{B}}$ & 0.29 & & & \\
\hline d 7 & $6.47^{\mathrm{B}}$ & $6.86^{\mathrm{B}}$ & 0.29 & & & \\
\hline d 14 & $8.07^{\mathrm{A}}$ & $7.58^{\mathrm{A}}$ & 0.29 & & & \\
\hline Media $^{2}$ & 7.24 & 7.28 & 0.41 & & & \\
\hline
\end{tabular}

${ }^{1}$ Os tratamentos foram: Controle e Curcumina (tratamento curcumina representa os animais que receberam 2 mg de curcumina diluída em 3 $\mathrm{ml}$ de óleo mineral via intra-mamária).

${ }^{2}$ Os resultados de dia 1 foram removidos do conjunto de dados para gerar a média por tratamento na análise estatística (EPM - erro padrão da média).

A-B Na mesma coluna, diferem $(\mathrm{P} \leq 0,05)$ ou tendem a diferir $(\mathrm{P} \leq 0,10)$, sendo ilustrado por letras maiúsculas diferentes.

a-b Na mesma linha, diferem $(\mathrm{P} \leq 0,05)$ ou tendem a diferir $(\mathrm{P} \leq 0,10)$, sendo ilustrado por letras minúsculas diferentes.

Fonte: Autores.

As bactérias identificadas no leite das ovelhas foram descritas na Tabela 3. Diversas bactérias foram identificadas, sendo mais comumente isolada foi Staphylococcus spp. 
Tabela 3. Bactérias identificadas nas amostras de leite das ovelhas com mastite subclinical nos dias 1, 7 e 14 dias após tratamento com curcumina (Experimento I).

\begin{tabular}{|c|c|c|c|c|}
\hline Animal & Grupo & Dia 1 & Dia 7 & Dia 14 \\
\hline 1 & Curcumina & $\begin{array}{l}\text { Staphylococcus spp. } \\
\text { coagulase negativa e } \\
\text { Candida spp. }\end{array}$ & Corynebacterium sp. & Corynebacterium sp. \\
\hline 2 & Controle & - & - & $\begin{array}{c}\text { Staphylococcus spp. coagulase } \\
\text { negativa. }\end{array}$ \\
\hline 3 & Controle & - & $\begin{array}{l}\text { Staphylococcus spp. } \\
\text { coagulase negativa }\end{array}$ & $\begin{array}{c}\text { Staphylococcus spp. coagulase } \\
\text { negativa }\end{array}$ \\
\hline 4 & Curcumina & Staphylococcus intermedius & - & - \\
\hline 5 & Curcumina & Candida $\mathrm{sp}$. & - & $\begin{array}{c}\text { Staphylococcus spp. coagulase } \\
\text { negativa }\end{array}$ \\
\hline 6 & Controle & $\begin{array}{l}\text { Staphylococcus spp. } \\
\text { coagulase negativa }\end{array}$ & - & - \\
\hline 7 & Controle & $\begin{array}{l}\text { Staphylococcus spp. } \\
\text { coagulase negativa e } \\
\text { Candida spp. }\end{array}$ & $\begin{array}{c}\text { Staphylococcus spp. } \\
\text { coagulase negativa }\end{array}$ & $\begin{array}{c}\text { Staphylococcus spp. coagulase } \\
\text { negativa }\end{array}$ \\
\hline 8 & Curcumina & $\begin{array}{l}\text { Staphylococcus spp. } \\
\text { coagulase negativa }\end{array}$ & - & - \\
\hline 9 & Controle & - & - & $\begin{array}{c}\text { Staphylococcus spp. coagulase } \\
\text { negativa }\end{array}$ \\
\hline 10 & Curcumina & $\begin{array}{l}\text { Staphylococcus spp. } \\
\text { coagulase negativa }\end{array}$ & Streptococcus uberis & Enterococcus faecalis \\
\hline
\end{tabular}

Fonte: Autores.

\subsection{Experimento II}

Efeito do dia foi observado para o grupo T2, isto é, houve um aumento na produção de leite do dia 1 para 20 (Tabela 4). Não houve efeito do tratamento e interação entre tratamento versus dia para produção de leite das ovelhas.

A contagem de células somáticas (CCS) sofreu efeito do tratamento, dia e interação entre tratamento versus dia (Tabela 4). O maior CCS foi observado no grupo T4. O efeito do dia foi em todos os tratamentos, sendo que após 3 dias aplicação o CCS elevou-se em aproximadamente 10 vezes quando comparado ao dia 1; sendo que essa contagem reduziu ao passar do tempo (dia 14), mas continuou elevado nos 4 grupos. A interação entre tratamento x dia mostrou que nos dias 3 e 14 o CCS foi maior no grupo T4 comparado ao controle.

Entre as 80 ovelhas, 17 tiveram problemas na glândula mamaria após a aplicação. Esses animais fizeram parte dos quatro tratamentos $(\mathrm{T} 0=5 ; \mathrm{T} 2=3 ; \mathrm{T} 3=4 ; \mathrm{T} 4=5)$, sendo que cinco ovelhas desenvolveram uma grave mastite ambiental e morreram em até 96 h pós início dos sinais clínicos; e os demais animais também testaram positivos para mastite subclínica no teste da raquete (Califórnia Mastite Teste) e 6 dessas ovelhas cessaram a produção de leite. 
Tabela 4. Produção de leite e CCS de ovelhas submetidas a diferentes doses de curcumina intra-mamária (Experimento II).

\begin{tabular}{|c|c|c|c|c|c|c|c|c|}
\hline \multirow{2}{*}{ Items } & \multicolumn{4}{|c|}{ Tratamento (Trat) ${ }^{1}$} & \multirow{2}{*}{ EPM } & \multicolumn{3}{|c|}{$P$ - valor } \\
\hline & Controle & $\mathbf{T} 2$ & T3 & T4 & & Trat & Dia & $\begin{array}{c}\text { Trat } x \\
\text { Dia }\end{array}$ \\
\hline Produção de & & & & & & 0.80 & 0.05 & 0.78 \\
\hline leite (g/dia) & & & & & & & & \\
\hline d 1 & 1060 & $1060^{\mathrm{B}}$ & 1055 & 1050 & 31.1 & & & \\
\hline d 20 & 1065 & $1129^{\mathrm{A}}$ & 1107 & 1106 & 32.7 & & & \\
\hline Média & 1063 & 1095 & 1081 & 1078 & 22.4 & & & \\
\hline $\operatorname{CCS}\left(\mathrm{x} 10^{3}\right.$ cel $)$ & & & & & & 0.02 & $<0.01$ & 0.04 \\
\hline d 1 & $395^{\mathrm{C}}$ & $241^{\mathrm{C}}$ & $289^{C}$ & $242^{\mathrm{C}}$ & 298 & & & \\
\hline d 3 & $2738^{\mathrm{A}, \mathrm{b}}$ & $2955^{\mathrm{A}, \mathrm{b}}$ & $3728^{\mathrm{A}, \mathrm{a}}$ & $3932^{\mathrm{A}, \mathrm{a}}$ & 298 & & & \\
\hline d 14 & $1664^{\mathrm{B}, \mathrm{b}}$ & $1061^{\mathrm{B}, \mathrm{b}}$ & $1509^{\mathrm{B}, \mathrm{b}}$ & $2539^{\mathrm{B}, \mathrm{a}}$ & 306 & & & \\
\hline Média $^{2}$ & $2254^{\mathrm{b}}$ & $1982^{\mathrm{b}}$ & $2602^{\mathrm{ab}}$ & $3211^{\mathrm{a}}$ & 289 & & & \\
\hline
\end{tabular}

${ }^{1}$ Tratamentos foram: controle $(0 \mathrm{mg})$ e T2, T3 e T4 representam os animais que receberam $2 \mathrm{mg}, 3 \mathrm{mg}$ e $4 \mathrm{mg}$ de curcumina diluída em $3 \mathrm{ml}$ de óleo mineral via intra-mamária, respectivamente.

${ }^{2}$ Os resultados de dia 1 foram removidos do conjunto de dados para gerar a média por tratamento na análise estatística (EPM - erro padrão da média).

A-B Na mesma coluna, diferem $(\mathrm{P} \leq 0,05)$ ou tendem a diferir $(\mathrm{P} \leq 0,10)$, sendo ilustrado por letras maiúsculas diferentes.

${ }^{a-b} \mathrm{Na}$ mesma linha, diferem $(\mathrm{P} \leq 0,05)$ ou tendem a diferir $(\mathrm{P} \leq 0,10)$, sendo ilustrado por letras minúsculas diferentes.

Fonte: Autores.

\section{Discussão}

As ovelhas que receberam curcumina via intra-mamária tiveram maior produção de leite, variando em torno de 0,3 a 0,4 litros mais que no controle. Semelhante a esse resultado, Jaguezeski et al. (2018), suplementou ovelhas diagnosticas com mastite subclínica com curcumina via dieta e também observou aumento na produção de leite, assim como cura de 5/6 ovelhas com mastite. Pesquisadores também verificaram que a suplementação de vacas com extratos de Curcuma longa contribuiu para elevar a produção de leite (Hashemzadeh-Cigari et al. 2014). Tais autores justificam a influência da curcumina a partir do metabolismo no trato gasto intestinal dos animais, fato esse que o presente estudo não aborda.

Estudos demonstram atividade antibacteriana da curcumina (Yun \& Lee, 2016), no entanto em nosso experimento I não foi verificado in vivo. Li et al. (2020) demonstraram potencial da curcumina contra Staphylococcus aureus, a principal bactéria isolada nas ovelhas com mastite desse estudo. Hipostenizávamos que essa atividade da curcumina poderia ser positiva na glândula mamaria, pois combateria as bactérias (curar a mastite) e assim poderia aumentar a produção de leite.

A composição centesimal do leite cru, relacionado a teores de proteína, lactose e sólidos não gordurosos foram menores para o grupo curcumina, não corroborando com Jaguezeski et al. (2018), que não demonstrou diferença nesses parâmetros quando suplementou com curcumina via dieta as ovelhas. Bencini e Pulina (1997) explicaram que normalmente quando ovelhas produzem mais leite tendem a apresentar uma relação inversamente proporcional com os níveis proteicos, acarretando a diminuição dos mesmos, como ocorreu aqui. No entanto, importante ressaltar que devesse considerar condições que os animais se encontram, fatores (raça, estágio de lactação, idade, infecção no úbere, manejo, dentre outros) que também influenciar na composição e na qualidade do leite (Larsgaard e Vaabonoe, 1993; Hassan, 1995; Bencini e Pulina 1997).

Observamos uma diminuição na contagem de eritrócitos em ambos os grupos e um amento de leucócitos também em ambos os grupos, não diferindo entre os tratamentos. Resultados que não corroboraram com Jaguezeski et al. (2018) que obteve resultados contrários quando a curcumina foi consumida junto ao concentrado, isto é, aumento de eritrócitos com o tempo e diminuição de leucócitos com o tempo para os animais. Contudo, apresentamos semelhança no fato dos valores encontrados estarem dentro dos valores de referência recomendados por Feldman et al. (2000). Ressaltamos que os animais do 
nosso estudo ainda se apresentavam em desafio por conterem CCS alta, indicando possível inflamação o úbere persistente, fato esse que pode mobilizar uma carga de leucócitos como agentes de defesa para controle da infecção, aumentando seus níveis como ocorrido.

No experimento II, o aumento na produção de leite ao longo do tempo de ovelhas saudáveis no grupo T2 foi interessante economicamente, fato esse que corroborou com o experimento I quando também foi usado $2 \mathrm{mg}$ de curcumina. Jaguezeski et al. (2018) forneceu concentrado com $100 \mathrm{mg} / \mathrm{kg}$ de curcumina na dieta de ovelhas leiteiras e esses animais tiveram maior produção de leite, associado a baixos de CCS. Estudos anteriores já comprovam uma relação inversa entre a produção de leite e o CCS, ou seja, quando a produção de leite estiver em alta os níveis de CCS estarão baixos e vice e versa (Martí et al. 2013; Caboni et al. 2017). As ovelhas do grupo T4 tiveram elevação de CCS no leite, mesmo não alterando a produção, prejudicando assim a qualidade do leite. A ideia de usar curcumina em bisnagas em ovelhas saudáveis tinha como objetivo principal reduzir CCS ainda mais, como tinha ocorrido quando a curcumina foi consumida (Jaguezeski et al. 2018); porém o inverso ocorreu aqui. Não podemos dizer que foi a curcumina responsável pelo aumento de CCS, assim como não podemos afirmar que foi o veículo (óleo mineral) visto que CCS aumentou em todos os grupos. Acreditamos que o aumento de CCS é consequência de diversos fatores, isto é, a solução introduzida na glândula mamaria, lesão no interior da glândula mamaria devido os animais não ficarem quietos durante a aplicação, assim como não podemos descartar a contaminação do canal do teto durante a aplicação. Na sequência, 17 animais desenvolverem mastite, 5 morrerem e aumento de CCS, chegamos à conclusão que não é indicado esse tipo de procedimento em animais saudáveis, pois a baixa no rebanho foi de 21,2\%; sem nenhum efeito positivo para as demais ovelhas $(n=63)$.

\section{Conclusão}

O uso da curcumina via intra-mamaria não tem efeito curativo, assim como quando usado em ovelhas saudáveis causa efeito negativo, afetando a qualidade do leite (elevou CCS). Além disso, a aplicação de produtos intra-mamários (óleo mineral ou óleo + curcumina) são um risco elevado para os animais, que podem contaminar-se durante a aplicação e desenvolver mastite subclínica ou ambiental, capaz de causar a morte. Apensar de ovelhas com mastite terem aumentado a produção de leite após receberam a aplicação de curcumina na glândula mamária, não tivemos a cura da mastite nesses animais.

\section{Agradecimentos}

Agradecemos a UDESC e a FAPESC que contribuíram financeiramente dia Edital de Pesquisa Aplicada.

\section{Referências}

Bencini, R. \& Pulina, G. (1997). The quality of sheep milk: a Review. Wool Technology and Sheep Breeding, 45(3), $182-220$.

Caboni, P., Manis, C. \& Ibba I. et al. (2017). Compositional profile of ovine milk with a high somatic cell count: A metabolomics approach. Int. Dairy J. 69, 33-39.

Deolindo, G. L., Molosse, V. L., \& Dilda, A., et al. (2021). Lacaune ewes with subclinical mastitis: effects of intramammary application of própolis. Research, Society and Development, $10(2)$.

Feldman, B. F., Zinkl, J. G. \& Jain, C. N. (2000). Schalm's Veterinary Hematology. 5th edn. San Diego: Academic Press, $932,2000$.

Galli, G. M., Da Silva, A. S. \& Biazus, A. H. et al. (2018) Feed addition of curcumin to laying hens showed anticoccidial effect, and improved egg quality and animal health. Research in veterinary science, 118, 101-106.

Hassan, H. A. (1995). Effects of crossing and environmental factors on production and some constituents of milk in Ossimi and Saidi sheep and their crosses with Chios. Small Ruminant Research, 18,165-172.

Jaguezeski, A. M., Perin, G. \& Bottari, N. B. et al. (2018) Addition of curcumin to the diet of dairy sheep improves health, performance and milk quality. Animal Feed Science and Technology, 246, 144-157. 
Research, Society and Development, v. 10, n. 15, e19101520262, 2021

(CC BY 4.0) | ISSN 2525-3409 | DOI: http://dx.doi.org/10.33448/rsd-v10i15.20262

Jaguezeski, A. M., Perin, G., \& Crecencio, R. B. (2018). et al. Addition of curcumin in dairy sheep diet in the control of subclinical mastitis. Acta Scientiae Veterinariae, 46(7).

Larsgard, A. G. \& Vaabenoe, A. Genetic and environmental causes of variation in mastitis in sheep. Small ruminant research, 12(3), 339-347, 1993.

Leitner, G., Chaffer, M. \& Shamay, A. et al. (2004). Changes in milk composition as affected by subclinical mastitis in sheep. Journal of dairy science, 87(1), $46-52$.

Li, T., Zhao, Y., \& Matthews, K. et al. (2021). Antibacterial activity against Staphylococcus aureus of curcumin-loaded chitosan spray coupled with photodynamic treatment. $L W T, 134,110073$.

Marti, A. D. O., Diaz, J. R. \& Molina, M. P. et al. (2013). Quantification of milk yield and composition changes as affected by subclinical mastitis during the current lactation in sheep. Journal Dairy Science. 96, 7698-7708.

Markey, B., Leonard F. \& Archambault M. et al. (2013). Clinical Veterinary Microbiology, segunda ed., Mosby Elsevier, London.

Molosse, V.; Souza, C. F. \& Baldissera, M. D. et al. (2019). Diet supplemented with curcumin for nursing lambs improves animal growth, energetic metabolism, and performance of the antioxidant and immune systems. Small Ruminant Research. 170, 74-81.

Noorafshan, A. \& Ashkani-Esfahani, S. (2013). A Review of Therapeutic Effects of Curcumin. Current Pharmaceutical Design. 19(11), $2032-2046$.

National Mastitis Council (NMC). (2004). Microbiological procedures for the diagnosis of bovine udder infection and determination of milk quality. quarta ed., NMC, Verona.

Park, Y. W., Juarez, M. \& Ramos, M. et al. (2007). Physico-chemical characteristics of goat and sheep milk. Small Ruminant Research. 68, 88-113.

Pereira, A. S., Shitsuka, D. M. \& Pereira, F. J. et al. (2018). Methodology of cientific research. [e-Book]. Santa Maria City. UAB / NTE / UFSM Editors. May, 14th, 2020.Available at: https://repositorio.ufsm.br/bitstream/handle/1/15824/Lic_Computacao_Metodologia-Pesquisa-Cientifica.pdf?sequence=1.

Rohenkohl, J. E., Correa, G. F. \& De Azambuja, D. F. et al. (2011). O agronegócio de leite de ovinos e caprinos. Indicadores Econômicos FEE. 39 (2).

Verissimo, C. J., Zafalon, L. F. \& Otsuk, I. P. et al. (2021). Prejuízos causados pela mastite em ovelhas Santa Inês. Arquivos do Instituto Biológico. 77, 583591.

Yun, D. G. \& Lee, D. G. (2016). Antibacterial activity of curcumin via apoptosis-like response in Escherichia coli. Applied microbiology and biotechnology. $100(12), 5505-5514$. 